\title{
ACTUARIAL BASIS OF COST ESTIMATES OF FEDERAL OLD-AGE INSURANCE
}

\author{
OTTO C. RICHTER*
}

The recommendations of the Committee on Economic Security leading to the Contributory Old-Age Benefit Plan established by the Social Security Act were formulated only after a large number of plans, involving a variety of provisions as to contributions and benefits, had been studied by the Committee and its staff. In the case of each of these plans, an important factor in its consideration was the element of cost, as estimated by the actuarial consultants to the staff. For the information of those who may be interested in this phase of the existing social security legislation, there follows a brief non-technical description of the assumptions and procedures underlying these cost estimates.

In actual practice it was frequently necessary, because of the limited time available, to develop estimates for a plan currently under consideration from related estimates applying to one or more plans previously considered. To avoid the confusing detail involved in tracing the step-by-step evolution.of such estimates, the present discussion will be limited to a description of basic assumptions and procedures as they relate to the plan finally adopted.

\section{Projection of Population.}

As a suitable basis for estimating the cost of public pension systems studied by the Committee, it was necessary at the start to obtain as accurate a picture as possible of the age distribution of the population in future years. To provide this statistical background, it was decided to project the present total population, by sex and age, for a period of 50 years in the future.

In selecting a period of $5^{\circ}$ years, it was'recognized that the true strain of pension benefits usually tends to be obscured by deceptively low disbursement requirements in the early years of operation of a plan, due to the fact that the group qualified for pensions in those years usually represents only a small fraction of the total group covered by the plan. As the plan continues in operation, however, the number and proportion of the total group eligible for pensions continue to increase, with a corresponding yearly increase in the amount required to pay pensions. In some plans-

\footnotetext{
- B.A., I923, University of Michigan. Chief Statistician's Division, American Telephone and Telegraph Company. Actuarial consultant to the Committee on Economic Security. Fellow of the Actuarial Society of America; Fellow of the Casualty Actuarial Society; Associate of the American Institute of Actuaries.
} 
such as that adopted in the Social Security Act-the average amount of pension per individual will also increase for many years, and in such cases the rate of increase in the annual amount required to pay pensions is considerably greater than if the average pension is relatively constant. Accordingly, illustrations of the year-to-year operations of the plan are likely to be misleading, unless the illustration is extended for a sufficient number of years to reflect the final level of average pensions and the ultimate relationship between the number of contributors and beneficiaries.

From the viewpoint of strict theory, the ultimate relationship between the age groups of a growing population would not be reached for a hundred years or more after the population has reached its maximum. It was found from test calculations, however, that, based on the assumed rates of mortality, the age distribution of the projected population 50 years hence would be sufficiently in line with the ultimate age distribution to make it unnecessary, as a practical matter, to carry the projection beyond that point.

\section{Assumptions Underlying Projection}

Starting with the total United States population of 122,775,000 as reported in the r930 Census, it was assumed that this population would increase gradually to a maximum of 150 million in 1975 and would continue at that level thereafter. The maximum population assumed to be reached in this country is substantially in line with that indicated by Thompson and Whelpton's "medium" estimates of population, as described in "Population Trends in the United States." The actual I930 figure was then connected with the estimated 1975 point by a smooth curve of the type characteristic of population-growth, with due regard to the trend of population prior to I930 and to its probable gradual approach to the maximum. The total population in each year, as read from the curve, provided a satisfactory basis for estimating the yearly increments by way of births which were required as balancing items in connection with the detailed projection of the population by sex and age.

As to mortality, it was assumed for the purposes of this projection that future mortality rates by age would be in accordance with those developed by the Bureau of the Census from the r920-I929 mortality experience of white males and white females in the Registration States of 1920 . These rates, which were made available to the Committee's staff through the courtesy of the Director of the Census, reflect a substantial improvement in the mortality of the general population since Igro, the central experience year of the last complete life tables developed from population statistics. In their present use, no direct allowance was made for further improvement in mortality, but the application of death rates for white lives to a total population including a substantial proportion of colored lives resulted in some indirect allowance for possibly lower mortality in future years.

An allowance for the effect of immigration and emigration upon the future population of the United States was made by assuming that departures would balance arrivals during the five years ending in I934, that there would be a net immigration 
of roo,000 persons annually during the succeeding five years, and that there would be a net immigration of 200,000 persons annually thereafter. This assumption is closely similar to that made by Thompson and Whelpton as an approximation of what might occur if the present immigration quotas applicable to the countries in the Eastern Hemisphere were filled, and similar quotas were established for countries in the Western Hemisphere. The age distribution of the groups added to the population by way of immigration was also derived from data in this respect given by Thompson and Whelpton.

\section{Results of Projection}

As a result of the above-described projection, there were made available, in a form suitable for cost studies, detailed estimates as to the sex and age distribution of the total population in each year from 1930 to 1980 , inclusive. It was clear from preliminary grouping and inspection of these results that they confirmed the conclusions of earlier investigators of population trends; namely, that this nation is facing, for many years to come, an increase not only in the number of aged persons, but also in the proportion of the total population included within this group. The projection indicated, for example, that the number of persons aged 65 and over would rise from slightly more than $61 / 2$ millions in $193^{\circ}$ to almost II millions in 1950 and to about 17 millions in 1980 . During the same period, the indicated proportion which this group formed of the total population increased from $5.4 \%$ in 1930 , to $7.7 \%$ in 1950 , and to $11.3 \%$ in 1980 .

It was appreciated by the Committee and staff that these specific estimates as to numbers and percentages involved assumptions which made them subject to a substantial probable error. At the same time, the unescapable trend toward an increasing number and proportion of the aged in the population obviously represented a factor of major significance which would need to be taken into consideration in drafting a public pension system having any reasonable prospects of permanence.

\section{Pensioners under Contributory Plan}

As a -first step in the construction of estimates relating directly to the operation of the contributory pension plan, there was derived from the detailed results of the population projection the numbers of persons at the end of each year at ages 65 and over who had reached age 65 after the calendar year 1941. These persons comprise the population group from which will be drawn the pensioners under a plan which starts in 1937 and requires, as a condition for eligibility to pension, a qualifying period of five years of insured employment prior to the attainment of age 65. The number in this group at the end of 1942 consisted solely of the persons reaching age 65 in that year, namely, those shown at age $6_{5}$ in the projected age distribution as of the end of the year. For the next year, the group consisted of the numbers shown at current attained ages 65 and 66 , these numbers representing those reaching age 65 in 1943 , plus the survivors of those who had reached age 65 in the preceding 
year. By proceeding in a similar fashion, that is, by adding for each succeeding calendar year the next age group above the highest included in the preceding year, there was built up the required data in regard to the total numbers in the projected population in each year who had reached age 65 after I94r.

The next step consisted in estimating the proportion of the above-determined group who would be eligible for pensions under the contributory plan. This involved an analysis of the application of the contributory plan to the population engaged in gainful occupations. From the age and occupational distribution of the gainfully occupied, as shown in the 1930 Census, there was deducted from each age group the number of persons whose occupational classification seemed to indicate that they would be excluded from the contributory plan; namely, the selfemployed, agricultural workers and domestic servants in private homes. The remaining numbers, comprising the gainfully occupied who presumably would be covered by the contributory plan, were then expressed as percentages of the total population in corresponding age groups. These percentages ranged from $43 \%$ at ages $20-24$ to $23 \%$ at ages $60-64$.

Assuming that the 1930 ratios of "insurable" employees (i.e., employees who would be covered by the contributory plan) to total population would prevail in future years, and that all employees covered by the plan would meet the requirement of employment in at least five different years before reaching age 65 , it followed that, for each age group in the population, the proportion qualified for old-age benefits upon attaining age 65 would be the maximum proportion of that age group who had been covered by the plan at any time during their prior period of active employment. For example, if $25 \%$ of the total population at age 60 were covered by the plan in 1937, the first year of operation of the plan, the same proportion of the total population reaching age 65 in 1942 would be qualified for old-age benefits. Similarly, if $45 \%$ of the population at age 25 were covered in 1937, the same percentage of the survivors of this group reaching age 65 in 1977 would be eligible for benefits at that time. Therefore, by applying such estimates of percentage coverage to the previously determined total population reaching age 65 after $194 \mathrm{I}$, an estimate of the accumulating number of pensioners under the contributory plan was obtained. In this connection, rough allowance was made for probable increases in the percentages of total population engaged in employments covered by the plan, reflecting both past trends in this respect and the added incentive in future years toward engaging in insurable employment, due to the operation of the plan itself.

\section{Estimated Coverage under Plan}

The numbers of employees under age 65 who would be covered by the contributory plan in future years were derived from the preceding analysis of the gainfully occupied, less employees excluded by reason of age or occupation from the provisions of the plan. The initial coverage was estimated at about $25^{1 / 3}$ million employees, and it was assumed that this group would gradually increase to a max- 
imum of 35 million in 1975 . This allowance for an increase in future years reflected the expected growth in the total population and in the numbers of insurable employees within the age groups covered by the plan.

\section{Assumption as to Average Annual Wage}

A review of available data in regard to the average wages of employees comprising the insurable group revealed that there was little reliable information concerning this factor. From an actuarial viewpoint, it would have been desirable, of course, to have accurate statistics for this group showing the level and trend of wages by age from the time of entrance into insurable employment until the attainment of age 65. With the exception of data for a few scattered companies, whose wage treatment obviously was not representative of that applicable to the insurable group as a whole, information in this detail was not available and could not be procured in time to be of use in connection with the studies in progress. With reference to the broader question of the average wage of all employees combined, some indications of this amount were provided by fairly recent studies which had been carried through by the Department of Labor. In using the results of these studies as a basis for estimating average wages over long periods in the future, however, it was necessary to make rough allowance for the depressing influence of current economic conditions on wage rates in recent years. After making what seemed to be reasonable allowance for this factor, it was assumed that the average earnings of insurable employees throughout the entire period covered by the projection would be $\$ 1,100$ per year, exclusive of the amounts by which individual salaries exceeded \$3,000 annually.

\section{Old-Age Benefits}

The average annuity benefit payable to employees qualifying for retirement in each year after $\mathrm{I} 94 \mathrm{I}$ was estimated by accumulating the individual employee's annual pay, at the average rate, over the assumed period of his employment under the plan, and by applying to the aggregate wages so determined the sliding scale of annuity percentages specified in the plan. The resulting average annuities by year of granting were then multiplied by the estimated number of pensioners on the roll in each year, distributed according to calendar year of retirement, in order to obtain for each year an estimate of total annuity disbursements in respect of all pensioners on the roll.

It may be noted that in estimating annuities on the basis of average wage rates, without reference to the dispersion of individual wages about the average, the resulting annuity tends to be overstated, since full effect is not given to the lower percentage rates specified by the annuity formula as applicable to aggregate wages in excess of $\$ 45,000$. In view of the fact that this overstatement would be limited to annuities granted after 195x, and that it appeared to be unlikely that the degree of 
overstatement in those later years would be sufficient to affect appreciably the estimated total disbursements for annuities, no adjustment was made for this factor.

A second factor which may appear to result in an overestimate of the annuity benefits to be granted in future years is contained in the assumption that employees will continue in employment from the time of their entrance into the contributory plan until they reach 65 years of age. Considered literally, this assimption obviously will not be borne out by future experience under the plan. Experience and reasoning clearly indicate that many presently covered individuals will not remain continuously in insurable employment until they reach age 65; for example, persons transferring to employments not covered by the plan, or women withdrawing from gainful employment altogether by reason of marriage.- The assumption was stated and used in this form, however, not in the thought that it represented a reasonable expectation as to the employment history of individuals, but rather as a convenient method of giving effect to an offsetting factor represented by employees first entering the insurable group in future years at advanced ages. Such additions to the group will tend to increase the annuity benefits payable in respect of a given amount of wages, due to the extra weight given to the first $\$ 3,000$ of aggregate wages paid to any individual in the computation of his oldage benefit. For example; an insured employee earning \$1, I00 per year from age 45 to age 65 would be entitled under the plan to an old-age benefit, starting at age 65 , in the amount of $\$ 30.83$ per month. If this individual were replaced after ro years of employment by a new entrant to the plan at the same age and pay, the taxes collected would not be changed, but the oldage benefits payable would be increased to $\$ 43.34$ per month, that is, $\$ 2$ r.67 to each of the two persons. The extent to which future withdrawals and additions to the insurable group will tend to offset one another in so far as pension costs are concerned must at present remain a matter for conjecture. As experience under the plan accumulates, the type of data required for measuring these elements of pension costs will gradually be made available.

\section{Payments upon Death}

The number of deaths among the insured group in each year of the projection was estimated by applying to the total number of contributing employees covered by the' plan composite mortality rates reflecting the current age distribution of this group. The composite rates applicable at the beginning and end of the projection period were computed in detail and the rates for the intervening years were obtained by interpolation. The average death benefit was estimated by accumulating the annual wage of individual employees, at the assumed average rate, from time of entrance into the plan until date of death, and taking $3 \frac{1}{2} \%$ of this amount as the average payment upon death. The estimated total payments upon death in each year covered by the projection -was then determined by multiplying the number of deaths by the average benefit. In these computations allowance was also made for 
estimated payments under the plan upon the death of retired employees receiving - old-age annuity benefits.

\section{Estimated Taxes under Plan}

The year-to-year revenue from the taxes levied by the Social Security Act for oldage benefit purposes was-estimated by applying the scheduled tax rates for each calendar year to the total payroll of the insurable group, as determined by multiplying the number of employees in the group. by the assumed average annual earnings of $\$ 1,100$. In this connection, it was not necessary to separate the excise tax on employers from the income tax on employees, since the equal tax rates in both cases are applicable to the same payroll base.

Expenses of administering the contributory plan were estimated at $81 / 3 \%$ of the total proceeds of the old-age benefit taxes where the combined tax rate upon employers and employees together was at the initial rate of $2 \%$ of payroll, $62 \% 3 \%$ where the combined tax rate was $3 \%$ of payroll, and $5 \%$ where the combined tax rate was $4 \%$ or more of payroll. These expense percentages were necessarily estimated on the basis of general considerations only, since at the time they were made details as to the administration of the plan were not available.

\section{Progress of Reserve}

The final step in estimating costs under the contributory plan consisted in bringing together the previously. described elements of cost and taxes in the form of a schedule showing the progress of the reserve arising from the operation of the plan. Following is a summary of this schedule as it appeared in a report submitted by the Senate Committee on Finance in connection with the introduction of the Social Security Bill. For the purposes of the Senate Committee's report, the figures comprising this schedule were converted from the calendar year basis, on which they had been prepared originally, to the basis of the government's fiscal year ending June 30 .

\begin{tabular}{|c|c|c|c|c|}
\hline \multirow[b]{2}{*}{$\begin{array}{l}\text { Fiscal Year } \\
\text { Ending } \\
\text { June } 30\end{array}$} & \multicolumn{3}{|c|}{ 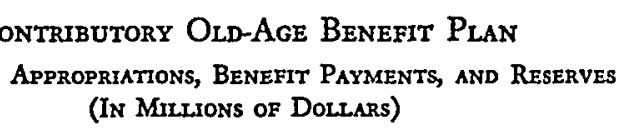 } & \multirow[b]{2}{*}{$\begin{array}{l}\text { Balance in } \\
\text { Reserve }\end{array}$} \\
\hline & $\begin{array}{l}\text { Appropriation } \\
\text { for Reserve }\end{array}$ & $\begin{array}{l}\text { Interest on } \\
\text { Reserive }\end{array}$ & $\begin{array}{c}\text { Bentefit } \\
\text { Payments }\end{array}$ & \\
\hline 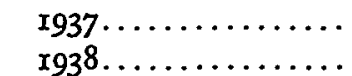 & $\begin{array}{l}255.5 \\
513.5\end{array}$ & $\begin{array}{l}0 . \\
7.6\end{array}$ & $\begin{array}{l}1.9 \\
7.2\end{array}$ & $\begin{array}{l}253.7 \\
767.5\end{array}$ \\
\hline r $939 . \ldots \ldots \ldots \ldots$ & 518.5 & 23.0 & 14.5 & $1,294.5$ \\
\hline 1940............. & 662.2 & 38.8 & 22.0 & $\mathrm{r}, 973.6$ \\
\hline 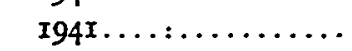 & 807.2 & 59.2 & 29.7 & $2,810.3$ \\
\hline I942................. & $8 \mathrm{r}_{4} .8$ & 84.4 & 52.8 & $3,656.6$ \\
\hline 1943 $\ldots \ldots \ldots \ldots \ldots$ & 970.0 & $\mathrm{x} 0 \mathrm{~g} .8$ & 94.2 & $4,642.1$ \\
\hline 1944............. & $1,126.6^{\circ}$ & r39.3 & 142.9 & $5,765.1$ \\
\hline I $945 \ldots \ldots \ldots \ldots \ldots$ & $x, 137.0$ & $\mathbf{x} 73.0$ & I91.2 & $6,883.9$ \\
\hline т946............. & $1,291.4$ & 206.5 & 249.2 & $8,132.7$ \\
\hline
\end{tabular}




\begin{tabular}{|c|c|c|c|c|}
\hline 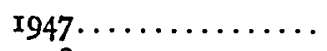 & $I, 447 . I$ & 243.9 & $3 \times 4.5$ & 9.509 .2 \\
\hline 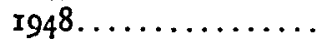 & $1,460.1$ & 285.2 & $377 \cdot 4$ & $10,877.0$ \\
\hline 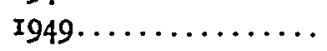 & $I, 621 . I$ & $3^{26.3}$ & 442.1 & $12,382.4$ \\
\hline 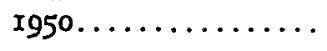 & $1,783.3$ & 371.5 & 505.5 & $14,031.7$ \\
\hline $1955 \ldots \ldots \ldots \ldots \ldots$ & $\mathrm{I}, 86 \mathrm{I} .2$ & $6 \mathrm{I}_{5} .8$ & 887.8 & 22, II 5.7 \\
\hline I $960 \ldots \ldots \ldots \ldots$ & I,939.I & $844 \cdot 2$ & $I, 379.9$ & $29,543.9$ \\
\hline$x_{965} \ldots \ldots \ldots \ldots \ldots$ & $2,016.9$ & $1,040.9$ & $\mathrm{I}, 844.0$ & $35,898.5$ \\
\hline 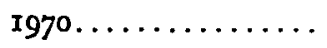 & $2,094.8$ & I,210.9 & $2,303.5$ & $4 \mathrm{I}, 366.7$ \\
\hline I $975 \ldots \ldots \ldots \ldots \ldots$ & $2,172.7$ & $\mathrm{I}, 34 \mathrm{I} .8$ & $2,872 . I$ & $45,368.3$ \\
\hline $1980 \ldots \ldots \ldots \ldots \ldots$ & $2,180.5$ & $1,406.0$ & $3,5 \mathrm{rx} \cdot 3$ & $46,942.7$ \\
\hline
\end{tabular}

The first column of the summarized schedule, headed "Appropriation for $\mathrm{Re}$ serve," represents the estimated net proceeds of the taxes called for by the contributory plan, after deduction of the estimated expenses of administering the plan. In this connection it should be pointed out that, while the provisions of the Social Security Act do not require Congress to appropriate the proceeds of these taxes to the Old-Age Reserve Account, it was assumed, for the purposes of these estimates, that the amount of the annual appropriations to the reserve would be determined on this basis.

The second column of the schedule, entitled "Interest on Reserve," represents interest credits at the rate of $3 \%$ per annum on the balance in the reserve at the end of the preceding year. In this connection, no adjustment was included for interest additions or deductions arising out of the current year's contributions and disbursements.

Benefit payments, as shown in the third column of the schedule, indicate the combined yearly disbursements for old-age annuity benefits and payments upon death, as determined by the previously described estimates. Since the contributory plan as finally adopted provides that old-age annuity benefits will start at age 65 only in case the employee has withdrawn from "regular" employment, the estimated old-age benefit payments included in this total are somewhat lower than those estimated, as previously described, on the assumption that these benefits would in every case start at the time the employee reached age 65. The reduction on this account reflects an average retirement age of about $67-1 / 2$ years. Whether or not this largely arbitrary assumption as to the average age at retirement will be borne out by future experience under the plan constitutes one of the major uncertain factors entering into the estimated costs of the plan.

The final column in the schedule shows the estimated balance in reserve at the end of each year from 1937 to 1950, inclusive, and thereafter at the end of quinquennial periods up to $x 980$. The yearly increase in these indicated balances in reserve represents, of course, the excess of current appropriations plus interest credits over current disbursements for benefits.

The figures on the last line of the schedule, that is, those relating to the year 1980 , are of major importance and interest, since they represent approximately the stabilized condition of the factors determining the cost of the contributory plan, if the plan 
continues to operate in accordance with its present terms and provisions, and if the assumptions and estimates entering into the projection are realized. It is important to note that the reserve called for by this program reaches a maximum of almost $\$ 47$ billion. The fact that interest on this reserve plus the current net proceeds of the old-age taxes are sufficient, with a little to spare, to meet the current disbursements under the plan, indicates that the plan is in actuarial balance. In other words, under the assumptions and estimates underlying this schedule, the present tax provisions of the contributory plan apparently are adequate to support the promised benefits.

\section{General Considerations}

It will be appreciated by the actuarially-minded that cost estimates such as those described in the foregoing-paragraphs are of limited significance as an indication of the absolute cost elements of a particular plan in future years. Such estimates served an essential purpose, however, in providing a basis for comparison of alternative provisions as to contributions, benefits and other factors, which were considered in formulating the Committee's recommendations in regard to the contributory plan. In this connection, it should be pointed out that assumptions which are based upon insufficient data, and which may therefore be subject to a substantial probable error, entered into each set of cost estimates and did not affect appreciably the relationship between the cost of separate plans. In other words, the resulting comparative costs were probably substantially accurate as a measure of specific differences between plans under consideration, and this was their primary purpose.

As to the estimates applicable to the plan finally adopted, considered by itself, they at least indicate the general magnitude of the undertaking, the developing relationship between income and outgo, and the nature of the financial problems involved. Whether or not these particular estimates of the amount of income and outgo will be borne out quantitatively is almost.wholly an academic question. For it is a practical certainty that the terms and provisions of the plan will be revised many times and in many ways before the period covered by these estimates has elapsed. 